\title{
ДОВЕРЕННОСТЬ: ФОРМА, СОДЕРЖАНИЕ, ВИДЫ
}

\section{POWER OF ATTORNEY: FORM, CONTENT, TYPES}

\section{N. Kulikova}

Summary: This article examines the legal analysis of the institution of representation in Russian civil law, including the Institute of irrevocable power of attorney, as well as identifying problems of legal regulation of irrevocable power of attorney, and formulating scientifically sound proposals for improving legislation.

Keywords: power of attorney, representation, authority, change of the civil code, irrevocable power of attorney, securing obligations.

\author{
Куликова Нина Николаевна \\ Московский финансово-промышленный \\ университет «Синергия» \\ ninochka2121985@yandex.ru
}

Аннотация: В данной статье рассматривается правовой анализ института представительства в российском гражданском праве, в том числе институт безотзывной доверенности, а также выявление проблем правового регулирования безотзывной доверенности, и формулировании научно обоснованных предложений по совершенствованию законодательства.

Ключевые слова: доверенность, представительство, полномочие, изменение ГК, безотзывная доверенность, обеспечение обязательств.

ствующих предметов правового регулирования (ГПК РФ, ТК РФ, СК РФ, КоАП РФ). Признаки понятий представительства, а также сущность этого действия прописаны в ст. 182 ГК РФ. В пункте 1 ст. 11 НК РФ прописано о том, что институты, понятия и термины гражданского, семейного и других отраслей законодательства, используемые в нём, применяются в том значении, в каком они используются В этих отраслях, если иное не предусмотрено НК РФ [4].

Доверенность как документ, содержащий элемент сделки, предъявляются соответствующие требования, прописанные Гражданским Кодексом РФ, а также в принятых в соответствии с ним иными нормативно-правовыми актами, которые не противоречат действующему законодательству.

Любая доверенность должна содержать следующие сведения: дату выдачи и место выдачи (совершения); сведения о доверителе и представителях, иначе говоря сведения о лицах чьи права и обязанности затрагиваются данным документом (в том числе со множественностью лиц на стороне как доверителей, так и представителей); перечень прав, обязанностей и сделок, на совершение которых уполномочивается представитель по данной доверенности; в данном документе необходимо указать о праве передоверения третьему лицу полномочий, выданных представителю; срок, на который выдаётся доверенность; подпись и расшифровка лица от имени, которого будет действовать представитель [2].

Действующим законодательством РФ предусмотрены разные формы доверенностей. Письменная форма доверенности предусматривает составление такого документа в нотариальной либо в простой письменной форме. В ст. 185 ГК РФ прописаны случаи, когда доверенность нужно удостоверять нотариально. К таким исключительным случаям относится безотзывная доверен- 
ность, выдаваемая от имени юридического лица, либо от имени действующего индивидуального предпринимателя, а также в том случае, когда выданные полномочия будут использованы при продаже недвижимого имущества доверителя. При продаже имущества от имени доверителя следует более детально прописать в доверенности полномочия представителя, а именно может ли доверенное лицо ставить подписи в договорах куплипродажи, может ли представитель получать денежные средства после совершения сделки, может ли подавать от имени доверителя иные предусмотренные законом формы заявлений, которые могут потребоваться для совершения сделки (внесение изменений в кадастровый учёт, запрос выписок из ЕГРН об объекте недвижимости, подача заявлений от имени доверителя о внесении изменений в регистрационную запись и иные).

Также существуют виды доверенностей, которые приравнены законом к нотариальным. Документы, которые соответствуют этим требованиям отражены в части 2 ст. 185 ГК РФ, а именно если документ выдаётся от имени юридического лица. В данном случае достаточно подписи руководителя, который имеет на это право согласно действующему уставу, либо иному документу, в котором отражены данные полномочия, и проставлением печати.

Доверенности отличаются по виду на разовые, специальные, генеральные. Разовые доверенности: они выдаются на совершение какого одного действия (например, на совершение купли-продажи определённого имущества доверителя, а также безотзывная форма доверенности).

Специальные доверенности: выдаётся на совершение целого ряда односторонних действий в течение одного времени (к примеру ведение дел в судах).

Генеральная доверенность: данный вид доверенностей выдаётся на право управления и распоряжения всего имущества доверителя. Само название доверенности говорит о том, что представителю даётся максимальное право действовать в отношении имущества доверителя. Но следует отметить, что даже при выдаче такого вида доверенности не может означать полноправное распоряжение имуществом лица, выдавшего данный документ.

В 2013 г. в отечественном праве появился, новый институт доверенностей - институт безотзывной доверенности, который регулируется статьями 188.1 ГК РФ. Ранее в российском гражданском законодательстве не существовало такого вида доверенностей. Появление института безотзывной доверенности в современной России было связано с совершенствованием гражданского законодательства, которое непосредственно касалось стремительно развивающегося крупного бизнеса и международной торговли, а также с инвестированием, в связи с поступательной интеграцией Российской Федерации в международную торговлю. Законодатель предусмотрел для представителя по доверенности возможность отказаться от полномочий в любое время, а доверителю - отменить доверенность. Такой подход был общим правилом при представлении интересов, исключением из которого стала безотзывная доверенность. Данный институт призван защищать права представителя, тогда как сам институт представительства в целом направлен в первую очередь на обеспечение интересов представляемого.

Под безотзывной, понимается доверенность, которая не может быть отменена до окончания срока её действия либо может быть отменена только в предусмотренных в ней случаях. Данный вид доверенности может выдаваться только в целях исполнения или обеспечения исполнения обязательства. Применение таких доверенностей возможно только в предпринимательских отношениях. Таким образом, в практической плоскости данная доверенность на практике будет использоваться профессиональными участниками рынка - юридическими лицами, индивидуальными предпринимателями. Это ограничение по право применению на сегодняшний день является оправданным, так как выдача безотзывной доверенности между физическими лицами на практике может породить благодатную почву для злоупотреблений со стороны представителей, например, в сфере купли-продажи недвижимого имущества [5].

В безотзывной доверенности может быть принципиально указано на невозможность её отмены в течение всего срока действия. Однако закон допускает указание в безотзывной доверенности тех случаев, при которых представляемый вправе отменить доверенность. Помимо этого, доверитель вправе отменить безотзывную доверенность при прекращении обязательства, а также для исполнения или обеспечения исполнения, которого, она была выдана. Таким образом, безотзывная доверенность может быть отменена.

При безотзывном представлении полномочий существует опасность того, что обладающий им представитель воспользуется своим положением и будет действовать во вред представляемому, не имеющему возможности прекратить недобросовестное поведение представителя. В целях предотвращения подобного, абзац 2 пункта 1 ст. 188.1 ГК РФ [1] предписывает, что при злоупотреблении или угрозе злоупотребления полномочием со стороны представителя представляемый может отменить выданное им безотзывное полномочие.

Для безотзывной доверенности обязательна нотариальная форма заверения, с указанием ограничения возможности её отмены [3]. Передоверие полномочий по безотзывной доверенности невозможно, если в содержании доверенности не предусмотрено иное.

Цели безотзывной доверенности прописаны в зако- 
не: исполнение или обеспечение исполнения обязательства. Можно сделать вывод о том, что законодателем вводится, новый способ исполнения по взятым обязательствам, ранее не прописанный Гражданским кодексом РФ. В связи с этим у юристов-практиков уже сейчас возникает вопрос о том, что безотзывная доверенность может фактически подменить собой использование залога, как способа обеспечения обязательства.

Безотзывная доверенность - это эффективный инструмент гражданского законодательства. Безотзывная доверенность станет популярной в гражданском обороте, поскольку это достаточно дешёвый, удобный и быстрый способ исполнить обязательство или обеспечить его исполнение.

Разберёмся в проблемных вопросах, связанных с право применением ст. 188.1 ГК РФ. При практическом применении встречаются случаи, когда безотзывная доверенность выдаётся на право представлять интересы доверенного лица в суде в ходе мероприятий, связанных с налоговым контролем. Отсюда вытекает вопрос о созвучности такой доверенности ст. 188 ГК РФ, а также на исполнение каких обязательств представляемого в данном случае направлена выдача безотзывной доверенности. Здесь следует обратить внимание на действующие

Методические рекомендации по удостоверению доверенности. В пункте 11.2 данного правового акта предусмотрено, что безотзывная доверенность должна иметь сведения об обязательстве, во исполнении или обеспечение которого она выдавалась.

Следует полагать, что доверенность на право представления интересов в суде не соответствует пункту 1 ст. 188.1 ГК РФ, поскольку реализация данных полномочий не направлена на исполнение обязательств представляемого. Вопрос о возможности выдачи доверенности на право представления интересов доверителя в суде носит актуальность в ситуации возникновения корпоративного конфликта. В условиях такого конфликта, связанной с многократной сменой высшего руководящего состава, действующих в интересах конфликтующих участников хозяйственного общества, вновь назначенный директор нередко отзывает доверенности, выданные ранее действующим директором, назначенным другой стороной конфликта.

Безотзывная доверенность выдаётся лишь в целях исполнения или обеспечения исполнения обязательства, представляемого перед представителем или лицами, в интересах которых действует представитель. Важно отметить, что сам по себе термин «безотзывная доверенность» не означает, что эту доверенность никогда нельзя отменить. Существуют основания для её отмены. Такие основания могут содержаться как в самом тексте доверенности, так и возникать при определённых обстоятельствах. К примеру, в случае прекращения обязательства, для обеспечения или исполнения которого безотзывная доверенность была выдана.

Также она может быть отменена в случае злоупотребления представителем своими полномочиями или при возникновении обстоятельств, очевидно свидетельствующих о том, что такое злоупотребление возможно в будущем, хотя конкретики в законе по этому случаю не имеется.

Вновь образованный институт безотзывной доверенности, имеет и свои недостатки, что, скорее всего, связано с тем, что существование начинает отчёт с 2013 г., и ещё не прошёл достаточно испытаний временем на прочность и эффективность. Так, с точки зрения логики, получается парадокс: законодатель предоставляет право «безотзывной» доверенности с тем условием, что её можно будет отменить или отозвать.

Есть ещё один спорный момент: могут ли такие доверенности быть условными, потому что если добавить условия, то сфера применения становится уже, но без условий можно не добиться поставленного результата. Возникает ещё один вопрос: как быть третьим лицам, которые согласно части 2 ст. 189 ГК РФ не знали и не должны были знать о том, что доверенность прекращена, если есть публикация об отзыве такой доверенности? Либо всегда их защищать как добросовестных, либо установить отмену безотзывной доверенности только в судебном порядке, как это предусматривалось в проекте Постановления Пленума Верховного Суда РФ от 23.06.2015 г. №25 [6], что являлось выходом из сложившийся ситуации.

Есть ещё один вопрос, который не освещён законодательно. Если доверенность выдаётся нескольким поверенным для осуществления ими полномочий совместно, то будет ли иметь силу такая доверенность после смерти одного из поверенных?

Передоверие полномочий по доверенности. Передоверие не может рассматриваться как самостоятельное основание возникновения представительства. Для того, чтобы осуществить выдачу доверенности в порядке передоверия, представитель должен иметь на это полномочие, которое будет являться правовым основанием передоверия. С вступлением в силу Федерального Закона от 07.05.2013 г. №100-Ф3 [8] ст. 187 ГК РФ претерпела существенные изменения. В части 1 закреплена возможность в тексте доверенности вовсе запретить передоверие, чего раньше не было.

Также появился своеобразный срок («разумный») для того, чтобы лицо, передавшее полномочия, известило об этом доверителя. Указано, в каких случаях передоверие не допускается. Закрепление законодателем факта сохранения соответствующих полномочий лицом, осу- 
ществившим передоверие (если иное не указано в доверенности и не установлено законом), является хорошим дополнением, так как ранее этот вопрос вызывал споры и дискуссии.

В рамках проведённой работы можно сделать выводы о том, что по претворению в жизнь норм применения в практической плоскости законов о безотзывной доверенности весьма много. Перечень оснований для прекращения безотзывной доверенности, отражённых в Ст. 188.1 ГК РФ, не является исчерпывающим и полным, так как ограничения касаются лишь прекращения действия доверенности. Вероятней всего, что в отношении безотзывной доверенности действуют и те основания прекращения доверенности, которые предусмотрены в пункте 1 ст. 188 ГК РФ, за исключением подпунктов 2 и 3.

Для того, чтобы избежать при практическом применении противоречий между нормами пункта 1 ст. 188 ГК РФ и пункта 1 ст. 188.1 ГК РФ, нотариусу разумно в тексте доверенности прописывать основания для прекращения доверенности. Не только применительно к безотзывным доверенностям, но и к доверенностям, которые выдаются в порядке передоверия, действует требование об исключительно нотариальной форме, в том числе, если безотзывная доверенность выдаётся юридическим лицом, руководителем филиала или представителем юридического лица.

В законодательстве необходимо установить запрет на передоверие в будущем по безотзывным доверенностям, в связи с чем в пункте 3 ст. 188.1 ГК РФ слова «если иное не предусмотрено в доверенности» исключить либо внести более точные пояснения, так как нынешнее содержание данной статьи может трактоваться двояко, что служит благодатной почвой для мошеннических действий со стороны недобропорядочных представителей.

По своей правовой природе безотзывная доверенность схожа с договором поручения. В связи с эти существует противоречие между нормами о договоре поручения и безотзывной доверенности, опосредующими отношения представительства, в части отмены доверенности, что влечёт возможность для доверителя избежать применения норм ст. 188.1 ГК РФ о безотзывной доверенности в том случае, если в основании её совершения лежит договор поручения, заключённый между доверителем и поверенным. Для разрешения противоречия необходимо пункт 2 ст. 977 ГК РФ доработать.

Институт доверенности, носит межпредметный характер. Согласно пункту 3 ст. 2 Гражданского Кодекса РФ к отношениям, связанным с имущественным характером, который носит административное или иное властное подчинение одной стороны другой, это относится в том числе к налоговым и другим финансовым, а также иным административным отношениям, гражданское законодательство не применяется, если иное не предусматривает действующее законодательство.

Проставление печати на бланке доверенностей, в том числе безотзывных, которые совершаются от имени юридического лица не требуется в тех случаях, когда доверенность юридического лица удостоверена нотариально, в связи с чем пункт 4 ст. 185.1 Гражданского Кодекса РФ необходимо уточнить. Представленные практические рекомендации могут способствует совершенствованию российского законодательства в области института представительств в целом, и безотзывных доверенностей в частности.

\section{ЛИТЕРАТУРА}

1. Гражданский кодекс Российской Федерации (часть первая) от 30.11.1994 г. №51-Ф3 (в ред. от 31.07.2020 г.).

2. Методические рекомендации по удостоверению доверенностей, утверждены решением Правления ФНП от 18.07.2016 г., протокол №07/16.

3. Основы законодательства Российской Федерации о нотариате (утв. ВС РФ 11.02.1993 г. №4462-1) (ред. от 27.12.2019г.) (с изм. и доп., вступ. в силу с 01.01.2020г.).

4. Федеральный закон «0 внесении изменений в подразделы 4 и 5 раздела I части первой и статью 1153 части третьей Гражданского кодекса Российской Федерации» от 07.05.2013 г. №100-Ф3 (последняя редакция).

5. Абакумова А.Я. Исторические аспекты формирования и развития института представительства в отечественном гражданском праве // Научная дискуссия современной молодёжи: актуальные вопросы, достижения и инновации. Сборник статей Международной научно-практической конференции. Пенза. 2019 г. С. 172-180.

6. Блинникова 0.А. Отдельные особенности безотзывной доверенности по законодательству Российской Федерации // Проблемы современного законодательства России и зарубежных стран. Материалы Международной научно-практической конференции. 2018 г. С. 182-190.

7. Постановление Пленума Верховного Суда Российской Федерации от 23.06.2015 г. №25 г. Москва «0 применении судами некоторых положений раздела I части первой Гражданского кодекса Российской Федерации» // Российская газета. Федеральный выпуск. 30.06 .2015 г. №140 (6711).

8. Коберник А.И. Правовая природа института представительства // Научные достижения и открытия. 2019 г. Сборник статей Международного научно-исследовательского конкурса. 2019 г. С. 223230.

(с) Куликова Нина Николаевна (ninochka2121985@уandex.ru). 